\title{
Causes and breakthroughs in the lack of motivation for technological innovation in private enterprises
}

\author{
CHEN Zhongwei, HE Lilong \\ School of economics, Sichuan University, research center of Sichuan University, Chengdu; \\ 610064, China
}

\begin{abstract}
Keywords: Technological innovation; private enterprises; motivation; policy recommendations
Abstract. The paper thinks that the protection of intellectual property rights system is not perfect, the technology innovation itself is a risk activity, technological innovation of private enterprise talent shortage as a result of technological innovation of private enterprise lack of motivation, by increasing the protection of intellectual property rights, through the sharing mechanism weaken the risk of technological innovation of private enterprises and the establishment of a disciplinary system to enhance the technology innovation intention of private enterprise.
\end{abstract}

\section{Introduction}

In the current complex macroeconomic environment, in the protection of intellectual property system in China and the lack of intellectual property protection consciousness is not strong in the environment of technological innovation in private enterprises, the higher cost of technological innovation of private enterprises can not be exclusive and easily by other enterprises a ride in the background, the shortage of private enterprises technical innovation. Therefore, to explore the construction of intellectual property rights protection system, resulting in torsional forced mechanism of technological innovation power of private enterprises, to promote technological innovation of private enterprise initiative and the development of the national economy, has practical significance.

\section{Literature review}

Many scholars have studied the technological innovation of private enterprises from different angles, which can be divided into the following categories:

(1) The reasons for technological innovation of private enterprises. Bai Xiujun believes that, in the new stage of development in the future, private enterprises should face the new problems arising from the further development, which have never been encountered before and must be solved. Among the many challenges, the most prominent is the technological innovation ability of private enterprises in China and the huge gap between enterprises in the world." Quan Yonghui said, "and the role of private enterprises in China's national economic and social development in the increasingly prominent position, has become the main force in China's economic construction, technology innovation is the lifeline of the competitiveness of private enterprises. To this end, private enterprises must choose their own technological innovation model, technological innovation for different markets, different technical fields, in order to enhance their economic strength." Zhang Qingchang believes that Chinese private enterprises take technological innovation as an important means of market access." Hu Zhengyue believes that "technological innovation is the driving force to promote economic development, but also an important magic weapon to form the core competence of enterprises."." Liu Haiyun believes that "technological innovation is the foundation of enterprise survival and development."'. Jia Shenghua believes that the private economy has become an important force in Zhejiang's economic growth and social progress. In the context of the weakening of the first mover advantage and the intensification of global competition, the urgent task is to cultivate the innovative development ability of private enterprises." Wang Qingxi believes that "technological innovation capability is an important source of competitive advantage for private enterprises."." Li Fumei believes that "technological innovation is the driving force of economic development, but also the key to improve the market competitiveness of enterprises and an important means to achieve enterprise goals."." 
(2) The technological innovation power of private entrepreneurs; Yuan Qing believes that the innovation power of private entrepreneurs in China mainly comes from the pursuit of material interests. The lack of spiritual demand for innovation behavior is the fundamental reason why entrepreneurs lack innovation power and lack innovation behavior." Zhang Guoliang believes that technological innovation is the source of small and medium-sized private enterprises to build a sustainable competitive advantage and gain excess profits in the market, as well as the driving force of new economic development."

(3)The plight of technological innovation of private enterprises. Pu Zusheng believes that the plight of technological innovation of private enterprises is mainly manifested in three aspects: lack of law, lack of resources and industrial correlation." Qin Ruijie believes that the "innovation mode selection, technological innovation risk and incentives are not in place, lack of knowledge and technological achievements, lack of awareness of intellectual property protection is not good at using external technology, information technology innovation process is not smooth and hinders the technological innovation of private enterprises. Chen Feiqiong believes that there are a series of obstacles in the technological innovation of private enterprises, such as funds, talents, innovation ability, management mechanism and enterprise scale." Bai Xiujun believes that the technological innovation dilemma of private enterprises stems from the system innovation of private enterprises in China can not be docking with the current market. Liu Pingyu thinks, "policy system, enterprise system and market system restrict the technological innovation of private enterprise", Sun Daoyin thinks, "capital and talent is the bottleneck factor of technological innovation of small and medium-sized private enterprises". Wang Hongda believes that "the lack of funds, lack of talent, lack of scientific strategic management of technological innovation and commitment to technological innovation risk difference was the main dilemma of technological innovation of private enterprises" and Liu Zhenyu believes that the lack of innovation and entrepreneurial spirit of financing difficulties and discriminatory tax policy, the lack of innovative talents, research ability and information ability is weak, technology innovation service support system areimperfect greatly obstructs the technological innovation of private enterprises." Tu Zhiling believes that there are many problems in the technological innovation of private enterprises in Nanjing, such as shortage of talents and funds, imperfect policy system and social service system, etc.".

(4)The private enterprises technological innovation policy recommendations. Wang Jijian believes that we can take measures to improve financing capacity, knowledge and technology accumulation, and strengthen the risk prevention measures to promote private enterprise technological innovation." Qin Ruijie thinks, "effective management of technological innovation process; strengthen the management of intellectual property rights, attach importance to the application of strategic alliances", these measures can improve the enthusiasm of private enterprises technological innovation. Chen Feiqiong believes that "guarantee the supply of funds and talent supply" is an effective measure to improve the technological innovation of private enterprises". $\mathrm{Pu}$ Zusheng believes that "the market allocation of human resources, broaden the channels of raising funds for innovation, and strengthen the legislation of cooperative innovation" can improve the technological innovation capability of private enterprises. Wang Sheng believes that the gradual strengthening of innovation and enterprise cluster model can promote the technological innovation of private enterprises in Wenzhou. Tang Hao believes that "enhancing innovation power, improving innovation ability, promoting innovation efforts, strengthening policy attraction and improving the application environment of innovation achievements" is an important measure to enhance the technological innovation capability of private enterprises. Bai Xiujun believes that institutional innovation is the path dependence of technological innovation of private enterprises. Li Ping believes that imitation innovation strategy and following innovation strategy are the main choice for private enterprises to carry out technological innovation". Guo Yanling believes that "information service" as an important content of the information system put into operation, the private enterprise technological innovation has an important role in promoting." Yuan Qing believes that, to enhance the innovation ability of private enterprises, we should start from cultivating innovative consciousness and improving the private entrepreneurs' spiritual demand for innovation". Chen Meili 
believes that the tax policy to encourage small and medium-sized private enterprises independent innovation specific measures." Liu Pingyu thinks, "should use the government, the private economy main body and the market three aspects innovation system to promote the private enterprise technological innovation." Li Chunyu believes that the introduction and imitation of re innovation is a realistic choice, the original innovation and integrated innovation is the inevitable choice, joint innovation is the basis for the innovation of private enterprises in china." Sun Daoyin believes that private enterprises can enhance their own innovation ability through enterprise mergers and acquisitions, personnel flow, equipment purchase, technology purchase, knowledge purchase and other open measures." Wang Hongda put forward some suggestions to improve the financing, technology source and enterprise system of technological innovation of small and medium-sized private enterprises in china. Lv Jun believes that the implementation of patent system can effectively promote the technological innovation of private enterprises". Shao Guirong believes that "cluster", which is between the enterprise and the market organization form, can promote the formation of technological innovation advantages of small and medium-sized private enterprises." Liu Zhenyu believes that the establishment of a multi-level financing system, strengthen the construction of technological innovation team, build "industry, University, research and production" combination of innovation platform, cultivate and improve the social service system." Guo Ping believes that the capital market is an important platform for the innovation and development of private enterprises." Wang Qingxi believes that private enterprises should improve their R \&amp; D conditions on the basis of more attention to enhance the technical level of their products. Transformation of the previous research and development methods rely on imitation and introduction, change passive to active, grasp the trend of technological development, improve product technology can not be imitated, leading the market technology trends." Ma Xuefeng believes that informal institutions such as concept, enterprise culture and entrepreneurship are of great significance to the successful innovation of enterprises." Li Fumei believes that "private enterprises need effective management in the process of technological innovation: the relationship between technology and market, organization and coordination of other departments; establish incentive system to control the risk of technological innovation; technological innovation process; to strengthen the effective management of intellectual property rights." Huang Jingbo believes that the gradual and cooperative mode of technological innovation is the better choice for technological innovation of private enterprises in china."

\section{The reasons for the lack of technological innovation motivation of private enterprises}

The reasons for the lack of motivation for technological innovation in private enterprises are analyzed in the following aspects:

\section{(1) Imperfect intellectual property protection system}

Property right has the function of encouragement and restriction, clear property right subject and perfect property right protection system have obvious promoting effect on enterprise's technological innovation. Generally speaking, technological innovation appears with certain inventions and inventions, and these inventions become a new kind of intangible assets. However, if the innovation results can not be protected by property rights, the value transformation of this intangible asset is not enough guarantee. Technological innovation as the foundation and source of intellectual property is the motive force of the modern intellectual property system to progress and development; provides an important guarantee and a good incentive effect and the construction of modern intellectual property system for technology innovation activities of the rich, can make the configuration and arrangement of various technical innovation related fields of Limited resources can be more optimization.

Through practice to verify previous shows, a country or a region to promote knowledge especially better all-round development of creation, dissemination and application of advanced high technology in, must set up more perfect protection and support system, and provide the corresponding good dynamic operation mechanism. In 1990s, Japan and South Korea and other countries have taken to 
build in line with their actual situation of international intellectual property system, to promote their domestic enterprises to learn foreign technology to more effectively, accelerate their development process of the technology. In our country, the international and domestic development environment facing the emergence of new fundamental changes, especially in the United States and the European Union to assume additional pressure and other traditional economic power countries in the political field of China's applied situation, in order to better and faster development of the national economy as the main target, to build a good market environment, continue to strengthen our country in various fields of enterprise competitive advantage, are proposed to build a strong era of intellectual property protection system, perfect requirements. In fact, in the course of development of China's modern economy and science and technology, especially the protection of intellectual property rights protection work for knowledge property rights problems in technology innovation is obviously strengthened, has achieved a lot of achievements, has become China's social economic development in the important foundation. But the development of the knowledge economy era from the present requirements there is still a very big gap, also need to solve the problems emerge in an endless stream, only by solving these problems, to ensure the development of the need to be better satisfied. In our country, the enterprise organization more beginning in the sense of great value for the intangible assets have a certain understanding, but to ensure that the intangible assets not only value, and value-added, more depends on the enforcement of intellectual property rights can not be achieved due to the standard. Therefore, to provide strong support for intellectual property rights is the key for enterprises to achieve significant economic benefits and constantly improve their market competitiveness.

From the overall situation, the current our country private enterprise the main body in the aspects of technological innovation in the protection of intellectual property rights awareness is relatively lagging behind, in this kind of assets can be achieved within the market value of cognition is insufficient, often lead to enterprises invested a lot of resources, and technological achievements after a long time before the completion of the development it is difficult to play its market value, or even a free transfer is not a normal phenomenon. According to statistics released the State Intellectual Property Office in China, the number of patent applications in 2008 the country's private enterprises reached 44700 , the scale in the same period the total patent scale occupy the ratio of less than $50 \%$, while at the same time, a total of 31888 patents of foreign enterprises to apply. The application of the scale of private enterprises occupy the ratio reached $95.8 \%$, the proportion is far more than in China. The above data is reflected in: first, the intellectual property has the scale, our country is in the unfavorable position, indicating that the overall level of awareness of IPR protection in China is relatively low; secondly, as the main force of modern technological innovation of private enterprises, innovation in the patent to be significantly better than similar foreign enterprises is weak, but also not in the aspect of intellectual property has its rightful position. Therefore, the above analysis shows that China's private enterprises in intellectual property protection consciousness is still relatively lagging behind, the vision that is not enough or sufficient capacity to ensure the acquisition of technology innovation's intellectual property successfully transformed into economic achievements to enhance their core competitiveness. The most important reason for the above situation lies in the fact that quite a number of private enterprises have not yet soberly recognized that intellectual property rights have become an important source of modern enterprise efficiency. Although our country has gradually set up some special laws for intellectual property protection, but it is difficult to effectively prevent the theft of intellectual property rights. If the intellectual property rights are embezzled by other subjects, then the private enterprises which invest and develop the intellectual property rights can not obtain the related income of innovation and development brought by this kind of knowledge. At present, there are mainly two aspects of the restriction of intellectual property protection in China's private enterprises: first, China's private enterprises are generally not patent protection did not take their own inventions habits, the main reason is that in the process of patent application, shall not pay a very high level of cost, also need to invest a lot of manpower and time and other types of resources, and the secret must be sufficient strength to protect technology; secondly, the private enterprises in the process of the use of intellectual property, in the case of a dispute, to pay the huge costs of litigation. 
Because of the restriction of intellectual property protection, resulting in some enterprises will take more short-term behavior, this situation has been reflected in technology innovation, it is difficult to performance and long-term development of the whole enterprise consistent for technology innovation activities. That is to say, in these enterprises, there may be one or several separate development of innovative projects, but it is difficult to construct a long-term innovation mechanism, therefore, persistent poor in terms of technology innovation. In fact, an effective property rights protection for knowledge, not just for the knowledge of the inventor of rights to provide adequate protection, which makes the research results can be developed more effectively, and ensure the smooth technology diffusion has been reversed, has become an important factor restricting the technological innovation of private enterprises.

\section{(2)Technological innovation itself is a risk activity}

Enterprises engaged in the technological innovation activity, will encounter many uncertainties, and thus produced a certain degree of risk, overall, private enterprises may face the risk of technology innovation mainly focuses on: the first is putting a lot of resources to implement research and development, but can not complete the relevant research; second because all also caused the research progress was prolonged, the study time far more than the original plan, will cause the enterprises do not have the ability to continue to provide adequate support for the innovative activities, leading to the initial investment is wasted; third is that this kind of research has made some achievements, but the level of R \&amp; D or d the process is far better than in other similar enterprises, thus losing the benefits. In the daily operation, if the private enterprise faces the problem of failure of research and development, or research results obtained in a backward state, indicates that the enterprise in the competition in this field is failure or in part failure. This result will lead to huge investment in enterprises in the early period of waste investment, therefore, enterprises will suffer huge losses because of this activity, so private enterprises will be daunting for technological innovation activities. Private enterprises in the process of technological innovation facing various types of risks, there are technical reasons, but also the impact of the market level. The reason lies in the technical level caused by these risks, private enterprises generally only the ability to carry out innovation activities of single technology development, and there is no way to carry out diversified research work so as to form a good situation of mutual support and mutual complement, so long as a technology development activities encounter some failures, for technical development work is equal to all the club of this kind of enterprises to become worthless. Secondly, the private enterprise is not only the development ability is insufficient, and based on the results of a certain technology, these results will achieve commercial ability is relatively weak, which is decided by the enterprises even in the stage of technology development and has achieved some success, or may be due to lack of funds and can not meet the needs of the market without success the results of the implementation of the market value of the conversion process, and can not guarantee the investment in technology development in the work reward. Due to excessive profit, risk and influence by factors such as cost, produce free riding, a large number of private enterprises to imitate, steal other enterprise innovation, influence the subjective initiative of the technological innovation of private enterprises as a whole.

\section{(3)Lack of technological innovation talents in private enterprises}

The core content of innovation activities smoothly lies in talent, and our country to engage in the development of science and technology talents mostly exist in universities and some professional research institutions, in addition, the main choice of large enterprise groups is this kind of talent, resulting in the most private enterprises are facing problems in the scientific and technical personnel. In addition, in private enterprises, as the income distribution system based on knowledge has not been effectively developed, in terms of social security mechanism construction is lagging behind, in addition, private enterprises generally adopt the family management pattern in the talent team construction also should be the introduction of the concept of traditional personnel, for the 
construction of the professional team do not give enough investment, therefore, the introduction of innovative talents in the training and efforts are relatively weak, this unfavorable situation determines the private enterprises for professional talent attraction to large enterprise and comparable, even this kind of enterprises within the existing professional and technical personnel will also appear the phenomenon of the loss. The State Council Development Research Center in the national private enterprises as the acquisition of a sample survey conducted in the activities of the data statistics and analysis, China's small and medium-sized enterprises have the technological innovation talents is confronted with the situation of lacking. In this survey, $47.46 \%$ of the enterprises surveyed have more than junior college staff, accounting for less than $5 \%$ of the total number of enterprises." Therefore, for this enterprise, the overall quality of staff is not high, poor technical ability and professional talents for the insufficient current situation, is the result of private enterprise is difficult to obtain important success factors and technological innovation spillover in the technological innovation activities.

\section{The policy recommendations to enhance the motivation of private technological innovation}

Private enterprise technological innovation can effectively improve the private enterprise market position, anti risk ability and enhance its contribution to the national economy. However, due to excessive profit, risk and cost by the influence of other factors, led to the technological innovation of private enterprises spillover, formation forced mechanism, reduce the autonomy of technological innovation of private enterprises, affecting the long-term development of private enterprises and the position in the national economy. Therefore, it is imperative to enhance the initiative of technological innovation of private enterprises and realize the benefits of technological innovation of private enterprises.

\section{(1) Strengthen the protection of intellectual property rights}

Intellectual property can be seen as the technology innovation activities of the soul, so, based on the realization of sustainable innovation, should strengthen the control of independent intellectual property rights at their disposal, update related technical staff and management personnel in the intellectual property rights awareness and concept of development makes organization and social professional research higher education institutions and other related subjects can better promote the work of intellectual property rights. At this stage, for the government, the primary work includes the following two aspects: first, to comprehensively strengthen propaganda, the intellectual property rights related laws and regulations have been effectively promoted in all personnel, the formation of intellectual property law concepts related to good in the whole society, in order to be able to start and build the rule of law in the society credit, social governance to promote related activities, provide excellent social atmosphere for the protection of intellectual property rights, for the whole society all kinds of personnel involved in the activities of technological innovation to build a good social atmosphere; at the same time, should actively improve the intellectual property infringement behavior and disciplinary efforts to combat, in this work should follow the law, the law; law enforcement must be strict, the basic principle of illegally ", so that private enterprises in innovation and investment The results obtained will not be infringed by illegality or violation.

Providing adequate protection for intellectual property rights is the basis for the smooth development and enrichment of technological innovation activities. In the process of development in the past, our efforts for the construction investment of intellectual property protection system is small, in addition, due to the adverse effects of local protectionism, it is difficult to avoid some businesses take fake way to obtain profits phenomenon. So, in order to promote the work of intellectual property rights are comprehensive onrush, also requires the majority of the private entrepreneurs in order to maintain the innovation achievement should not be infringed at the same time, must be on the market for illegal violations of intellectual property rights make resolute struggle, so that innovation has 
become a real source of competitiveness, the innovation activities become the basic factors of market and grow more win.

\section{(2)Reduce the risk of technological innovation of private enterprises through sharing mechanism}

We should actively build and improve the social service system and risk sharing mechanism, so that private enterprises can obtain more comprehensive professional services and risk diversification when they engage in technological innovation. It can be promoted in the following aspects. (1) construct and perfect the professional technical innovation service center. Should the technology innovation service center development and rich has established the service functions, to better integrate various social resources of science and technology work, the use of new technology innovation service platform, so that private enterprises can get more sufficient information, technology, personnel, financial and legal aspects of professional services in the technological innovation activities. (2) information network flow between the construction of colleges and universities, professional research institutions, industry associations, enterprises and other entities, provide adequate information support for the innovation and development of private enterprises, released the results of the use of innovative network information platform for the first time, the successful implementation of technology innovation and development work to help private enterprises to the. (3) the joint and supervisory role of developing industry associations. Industry Association to help predict the development of enterprises in the industry technology at the present stage and future development trend, the relevant government departments to support private enterprises as the main object, the design and the introduction of more in line with the needs of industrial policy and industrial technology policy, as well as supporting the construction industry good strategic planning, to help private enterprises to grasp the direction of technological innovation, at the same time, industry associations can also effectively prevent the technological innovation spillover.

\section{(3)Promote the construction of professional team, and form a good innovation culture}

The main body of technological innovation is man. Private enterprises should pay full attention to the talents, management policies and measures to attract and retain the talent, and gradually form a strongly in the sense of innovation, in the spirit of innovation and innovation of modern advanced professional team, to further promote the smooth implementation of technological innovation research and development activities. (1) private enterprises should form an open channel of talent flow inside, and formulate and implement a set of talent policy with market competitiveness, so as to realize the introduction and cultivation of professional innovative talents. The key to build a favorable talent construction, as well as the use of performance evaluation and incentive mechanism of internal management, guided by the relevant staff burst strong work enthusiasm, help them to have stronger innovation ability. In addition, the management should be through various policies and measures, and actively promote the technology participating in distribution of private enterprises diversified forms, the intellectual capital in the proportion of shares corresponding to the good, the various aspects of the work of all efforts to ensure the private enterprise has better attract talent mechanism, and makes the international the domestic variety of talents can effectively gather private enterprises, promote technological innovation activities more efficient and lasting. (2) technology should increase professional staff work through various forms of training, more diverse and more practical on-the-job training and continuing education activities, continue to improve the internal technical personnel in carrying out the work of scientific research literacy. Therefore, should be constructed to meet the need of different types of talents training activities, including the integrated use of enterprise self training, study and education combined way out of various types, enhance their professional ability of long-term culture innovation. 


\section{(4)Establish strict disciplinary system to curb the spillover of technological innovation results in private enterprises}

Punishment and encouragement constitute the two level of market economy. The market economy system itself provides a strong incentive, but there is a lack of strong disciplinary system." The technological innovation achievements of private enterprises are often stolen or imitated, the important reason is that the cost of this method is low, the effect is remarkable and the punishment is unfavorable. For example, when the intellectual property rights of private enterprises to be stolen or copied, through legal means to regain innovation is long, need to spend a lot of energy, manpower, material and financial resources, even if successful innovation will take the court at most of the companies involved a small fine, fine is not worth mentioning for these companies involved, is not enough to make up for the loss of the enterprise innovation. At the same time, even if private enterprises invest a lot of money and manpower for technological innovation, technological innovation has created a leading level, also can not get enough attention of the state and governments at all levels and rewards. Therefore, in order to protect the technological innovation achievements of private enterprises, we should establish a strict disciplinary system and a strong incentive system, which can be referred to the western countries, the United States and Japan and other developed countries. Japan and the United States and other countries to protect intellectual property rights and closely combined with the criminal law, criminal penalties for intellectual property crimes, its severity is enough to deter criminals. Through legislation, criminal penalties for serious violations of intellectual property rights are strengthened, which represents the development trend of current intellectual property legislation. At present, China's intellectual property disputes only stay in the civil phase, deterrence is not enough, it should rise to the criminal phase, deter criminals.

\section{Acknowledgements}

This is the "policy and implementation of Sichuan Province Philosophy Social Sciences Major tender driving strategy in Sichuan province innovation industry" (SC13ZD05) "and the 2015 National Social Science Fund Project" youth precise poverty targeting mechanism and policy efficiency research "(15CJL057) initial results.

\section{Reference:}

[1] Zhang Qingchang, Tang Hong, technological innovation of Chinese private enterprises under the condition of asymmetric information: [J] industrial economy research 2011 (01).

[2] Liu Haiyun studies on technological innovation and intellectual property protection of private enterprises: technology and management 2010 (05).

[3] Wang Qingxi, Qin Hui's technological innovation capability and the competitive advantage of private enterprises: An Empirical Study of Science (2007) (12).

[4] Ma Xuefeng: informal institutional arrangement for technological innovation of private enterprises (2007) (06).

Technical innovation and management of [5] Li Fumei private enterprises: 2011 (05).

[6] Huang Jingbo private enterprise's survival mode and technological innovation of Journal of South China University of Technology 2005 (01). 